\title{
CLINICO-PATHOLOGICAL STUDY AND MANAGEMENT OF DUODENAL ULCER PERFORATION
}

Sreenidhi G.M1, Nandeeshkumar G.N²

HOW TO CITE THIS ARTICLE:

Sreenidhi GM, Nandeeshkumar GN. "Clinico-pathological study and management of duodenal ulcer perforation". Journal of Evolution of Medical and Dental Sciences 2013; Vol2, Issue 34, August 26; Page: 6553-6560.

ABSTRACT: NEED FOR STUDY: Acute perforation of the duodenal ulcer produces one of the most dramatic pictures of acute abdominal catastrophe. The classical board like rigidity and its associated life threatening complications are quite striking in most cases. Smoking and alcohol are known co morbid factor known to be associated with duodenal ulcer perforation. The mean prevalence of $\mathrm{H}$. Pylori infection in patients with perforated duodenal ulcer is $60 \%$ as compared with $90 \%-100 \%$ in uncomplicated ulcer. Collier and Pain speculated that the elderly, taking NSAIDS are particularly susceptible to the development of perforated duodenal ulcer. The perforated viscous challenges the surgeons skill as a technician and his knowledge of pre operative, intra operative, care of severely ill patients. Majority of patient with sudden onset of abdominal pain a high index of suspicion is essential to diagnose hollow viscous perforation early, as significant mortality and morbidity result from diagnostic delay. Factors such as concomitant disease, shock on admission, delayed surgery (more than 24 hours), post operative abdominal and wound infection have been associated with increased morbidity and mortality in ulcer patients. In spite of better understanding of disease, effective resuscitation and prompt surgery under modern anesthesia techniques, there is high morbidity and mortality. Hence, attempt has been made to analyze the various factors that are affecting the morbidity and mortality of patients with duodenal ulcer perforation. METHODS: The study population consisted of patients who are admitted with duodenal ulcer perforation, which was clinically diagnosed and supported by radiological examination and sonological examination. A proforma drafted for study of these patients was used. Patient was examined systematically giving importance to clinical examination. A treatment was instituted appropriately and follow up done. RESULTS: Most of the cases were due to perforation of duodenal ulcer in the anterior wall of first part of the duodenum. Most patients who presented early had good recovery with minimal post operative complications. Patients who presented late more than 48 hours after perforation had high post operative complications and high mortality rate. Recovery of the patient also depends on the size of perforation, more the size of the perforation more the chances of presenting with leak and more complications. H. Pylori is a major risk factor for duodenal perforation. Perforation is more common in patients with history of smoking and alcoholism. INTERPRETATION AND CONCLUSION: Duodenal ulcer perforation is quite common among the patients with peptic ulcer disease with history of chronic smoking and alcoholism, commonly in males. Large group has delayed presentation, which has significant impact on the increased mortality and morbidity of the patient. Poor condition of the patient at the time of the admission worse is the prognosis. Diagnosis is mainly by the clinical examination and confirmation by $\mathrm{x}$ ray examination. Main treatment done is simple closure of perforation with peritoneal lavage. Early diagnosis and prompt management of shock and septicemia is important for better prognosis of patients.

KEYWORDS: Peptic ulcer perforation, duodenal ulcer, Simple closure. 
INTRODUCTION: Duodenal ulcer is one of the most common malady that affects the mankind in south India. Though lot of work had been done on the etiology this condition, one specific etiological agent cannot be incriminated in the causation of this particular disease especially in our part of country. Since, stress forms the most important single feature in causing peptic ulcer and today's modern life is full of stress and strain, this condition is on the increase. Perforation of gastric or duodenal ulcer is one of the most serious and most overwhelming catastrophic that is affecting human being. Among abdominal emergencies, perforations of peptic ulcer are third in frequencies, acute appendicitis and acute intestinal obstruction being more common. Prompt recognition of the condition is very important and only by early diagnosis and treatment it is possible to reduce the relatively high mortality. There is decline in incidence of duodenal ulcers and elective surgery for duodenal ulcer which is attribute to the era of $\mathrm{H} 2$ blockers and proton pump inhibitors, which provides symptomatic relief to patients. But the percentage of patients with perforation has not declined, probably due to increased inadvertent use of NSAIDS, corticosteroids and because of irregular use of H2 antagonist drugs. The treatment of perforation still continues to be controversial. Just closure of the perforation may save life, but chance of recurrence of ulcer is too high and patient may not turn up for a second curative surgery. So, there is a school of thought, which recommends definitive surgery in a perforated peptic ulcer. This may to a certain extent reduce the mortality and morbidity of the patient, because patients have to risk major operation when the general condition is not good. On the other hand it saves the patient from further surgery. When acute or chronic duodenal ulcer perforates into the peritoneal cavity, three components require treatment viz, the ulcer, perforation and the resultant peritonitis. The perforation and the resultant peritonitis are immediate threats to life, the ulcer in itself is not. The therapeutic priorities thus are treatment of peritonitis and securing the closure of perforation which may be achieved with surgical procedure. In spite of better understanding of disease, effective resuscitation and prompt surgery under modern anesthetic techniques, there is high morbidity (36\%) and mortality (6\%). Hence, attempt has been made to analyze the various factors, which are affecting the morbidity and mortality of the patients with duodenal ulcer perforation.

AIMS AND OBJECTIVES: The aim of this study is to study 50 cases of duodenal ulcer perforation and

1. Demographic profile

2. Spectrum of clinical investigations

3. Etiology, evaluate lab investigations and radiological investigations.

4. Bacteriological investigations

5. To study the influence of TB and immune-compromised disease leading to increased incidence of duodenal ulcer perforation.

6. To evaluate efficacy, recurrence rate, complications, morbidity and mortality, duration of hospital stay associated with management strategies.

7. All patients were operated after adequate resuscitation.

8. To study the incidence of H. Pylori in duodenal ulcer perforation.

METHODOLOGY: All patients of duodenal ulcer presenting to the department of surgery, KIMS hospital, Bangalore over a period of three years (October 2009 to April 2011). With clinical, sonological, radiological features of duodenal ulcer perforation.

\section{Inclusion criteria:}


1. Patient aged more than 18 years

2. Patient presenting with duodenal ulcer perforation

\section{Exclusion criteria:}

1. Patient aged less than 18 years

2. Patient with trauma are excluded.

Sample size: 250 cases.

The study was approved by the ethical committee of our hospital. Totally 250 cases who presented to the Department of surgery, KIMS hospital, Bangalore over a period of one and a half years (October 2008 to April 2011)

Fulfilled the criteria's and were included in the study. All the cases for the present study were taken after thorough general physical examination, Routine blood investigations, erect X-ray abdomen, and ultrasonography were done. Comparison was done between the samples on the following parameters:

\section{OBSERVATIONS:}

1. Age distribution

\begin{tabular}{|c|c|c|}
\hline Age in years & No of patients & $\%$ \\
\hline $17-20$ & 40 & 16.0 \\
\hline $21-30$ & 55 & 22.0 \\
\hline $31-40$ & 35 & 14.0 \\
\hline $41-50$ & 55 & 22.0 \\
\hline $51-60$ & 45 & 18.0 \\
\hline $61-70$ & 15 & 6.0 \\
\hline$>70$ & 5 & 2.0 \\
\hline Total & 250 & 100.0 \\
\hline
\end{tabular}

2. Gender distribution

\begin{tabular}{|c|c|c|}
\hline Gender & No of patients & $\%$ \\
\hline Male & 230 & 92.0 \\
\hline Female & 20 & 8.0 \\
\hline Total & 250 & 100.0 \\
\hline
\end{tabular}

3. Risk factors

\begin{tabular}{|c|c|c|}
\hline Risk Factors & No of patients $(\mathrm{n}=250)$ & $\%$ \\
\hline Smoking & 120 & 48.0 \\
\hline Alcohol & 160 & 64.0 \\
\hline NSAIDS & 55 & 22.0 \\
\hline Steroids & 5 & 2.0 \\
\hline
\end{tabular}




\section{ORIGINAL ARTICLE}

4. Mode of presentation:

\begin{tabular}{|c|c|c|}
\hline Symptoms & Number of patients(n=250) & $\%$ \\
\hline Pain & 250 & 100.0 \\
\hline Distension & 235 & 94.0 \\
\hline Vomiting & 190 & 76.0 \\
\hline Fever & 90 & 36.0 \\
\hline
\end{tabular}

\begin{tabular}{|l|c|c|}
\hline \multicolumn{1}{|c|}{ Signs } & No. of patients $(\mathrm{n}=250)$ & $\%$ \\
\hline Distension & 235 & 94.0 \\
\hline Guarding & 245 & 98.0 \\
\hline Rigidity & 245 & 98.0 \\
\hline Absent bowel sounds & 250 & 100.0 \\
\hline Obliteration of liver dullness & 220 & 88.0 \\
\hline Tenderness & 250 & 100.0 \\
\hline Shock & 50 & 20.0 \\
\hline
\end{tabular}

5. Incidence of H.pylori in perforation (Biopsy findings)

\begin{tabular}{|c|c|c|}
\hline H.Pylori & Number of patients $(n=250)$ & $\%$ \\
\hline Yes & 145 & 58.0 \\
\hline No & 105 & 42.0 \\
\hline
\end{tabular}

6. Comparison of baseline variables and clinical variables according to incidence of $\mathrm{H}$. Pylori

\begin{tabular}{|l|c|c|c|}
\hline \multicolumn{1}{|c|}{ Variables } & No(n=105) & Yes(n=145) & P value \\
\hline Age in years & $20.05+-16.07$ & $40.14+-15.42$ & 0.984 \\
\hline Gender(M:F) & $85: 20$ & $145: 0$ & 0.026 \\
\hline Smoking & $45(42.9 \%)$ & $75(51.7 \%)$ & 0.536 \\
\hline Alcohol & $70(66.7 \%)$ & $95(65.5 \%)$ & 0.933 \\
\hline NSAIDs & $20(19.0 \%)$ & $35(24.1 \%)$ & 0.668 \\
\hline Steroids & 0 & $5(3.4 \%)$ & 1.000 \\
\hline Guarding & $100(95.2 \%)$ & $145(100 \%)$ & 0.420 \\
\hline Rigidity & $20(95.2 \%)$ & $29(100.0 \%)$ & 0.420 \\
\hline
\end{tabular}

7. Follow up endoscopy

\begin{tabular}{|c|c|c|}
\hline Endoscopy & Number of patients $(\mathrm{n}=120)$ & $\%$ \\
\hline Negative & 116 & 96.5 \\
\hline Positive & 4 & 3.4 \\
\hline
\end{tabular}




\section{ORIGINAL ARTICLE}

8. Procedure

\begin{tabular}{|l|c|c|}
\hline \multicolumn{1}{|c|}{ Procedure } & Number of patients $(\mathrm{n}=250)$ & $\%$ \\
\hline Laparotomy and Grahams patch & 245 & 98.0 \\
\hline Laparoscopy and procedure & 5 & 2.0 \\
\hline
\end{tabular}

9. Radiological investigations

\begin{tabular}{|c|c|}
\hline Plain X-ray abdomen (Erect) & No. of cases \\
\hline Positive & 97 \\
\hline Negative & 1 \\
\hline
\end{tabular}

10. Site of perforation

\begin{tabular}{|c|c|c|}
\hline Site of perforations & No. of cases & $\%$ \\
\hline First part of duodenum, anterior & 102 & 98.0 \\
\hline Second part of duodenum, anterior wall & 7 & 2.00 \\
\hline
\end{tabular}

11. Size of perforation:

\begin{tabular}{|c|c|c|}
\hline Size of perforation & No of patients $(\mathrm{n}=250)$ & $\%$ \\
\hline $0.1-0.5$ & 85 & 34.0 \\
\hline $0.5-1.0$ & 150 & 60.0 \\
\hline$>1.0$ & 15 & 6.0 \\
\hline
\end{tabular}

12. Size of perforation Vs complications

\begin{tabular}{|c|c|c|}
\hline \multicolumn{2}{|c|}{ Complications } \\
\hline Size of perforation & Absent & Present \\
\hline $0.1-0.5$ & $75(37.5 \%)$ & 0 \\
\hline $0.5-1.0$ & $125(62.5 \%)$ & $35(70.0 \%)$ \\
\hline$>1.0$ & 0 & $15(30.0 \%)$ \\
\hline Total & $200(100 \%)$ & $50(100.0 \%)$ \\
\hline Mean+-SD & $0.57+-0.24$ & $1.03+-0.33$ \\
\hline Inference & $\begin{array}{l}\text { Incidence of complications are } \\
\text { significantly associated with } \\
\text { larger size of perforations with } \\
\text { p<0.001 }\end{array}$ \\
\hline
\end{tabular}

13. Total hospital stay In days

\begin{tabular}{|c|c|c|}
\hline Total hospital stay in days & Number of patients $(\mathrm{n}=250)$ & $\%$ \\
\hline $1-10$ days & 200 & 80.0 \\
\hline $11-20$ days & 15 & 6.0 \\
\hline $21-30$ days & 25 & 10.0 \\
\hline$>30$ days & 10 & 4.0 \\
\hline
\end{tabular}


14. Duration of hospitalization varied with postoperative complications

\begin{tabular}{|c|c|c|}
\hline Duration of hospital stay & Absent & Present \\
\hline $1-10$ days & $195(97.5 \%)$ & $5(10.0 \%)$ \\
\hline $11-20$ days & $5(2.5 \%)$ & $10(20 \%)$ \\
\hline $1-30$ days & 0 & $25(50.0 \%)$ \\
\hline$>30$ days & 0 & $10(20.0 \%)$ \\
\hline Total & $200(100.0 \%)$ & $50(100.0 \%)$ \\
\hline Mean+-SD & $8.85+-1.07$ & $22.90+-9.24$ \\
\hline Inference & $\begin{array}{l}\text { Duration if hospital stay is } \\
\text { significantly more in patients } \\
\text { with complications with } \\
\text { p<0.001 }\end{array}$ & \\
\hline
\end{tabular}

15. Complications of patients studied

\begin{tabular}{|c|c|c|}
\hline Complications & Number of patients $(\mathrm{n}=250)$ & $\%$ \\
\hline None & 200 & 80.0 \\
\hline Yes & 50 & 20.0 \\
\hline Bronchopneumonia & 15 & 6.0 \\
\hline Wound infections & 20 & 8.0 \\
\hline Renal failure & 5 & 2.0 \\
\hline Burst abdomen & 5 & 2.0 \\
\hline Death & 5 & 2.0 \\
\hline
\end{tabular}

DISCUSSION: Duodenal ulcer perforation is one of the commonest surgical emergencies. Although incidence of surgery for duodenal ulcer disease has reduced drastically with advent of proton pump inhibitors and $\mathrm{H} 2$ receptor antagonist, but surgery for perforations has not changed.

Age incidence: Duodenal ulceration is common in the age group of 20-30 years and 40-50 years in our study, but age is no bar for perforation to occur. It has also been reported in 4 years old infant.

Sex incidence: In our study series $92 \%$ were males and $84 \%$ were females, and the malefemale ratio being 11.5:1. Perforation is more common in males than females, because males were subjected to more stress and strain of life and female sex hormone offers some security against perforation as claimed by Skovgaard.

Risk factors: Among 50 patients 32 patients had history of alcoholism. The incidence is more in cases of smokers and alcoholics. There is increasing incidence among NSAIDS user.

Clinical presentation of perforations: In the present study, pain was present in all cases of duodenal ulcer perforation, indicating that the pain was the most common symptom in duodenal ulcer cases. Guarding and rigidity was present in $98 \%$ of cases. All patients had absent bowel sounds.

Incidence of H. Pylori: We were able to analyze the H. Pylori infection by taking ulcer edge biopsy (histopathological examination); the incidence of H. Pylori in present study was 58\%. 
Comparison of baseline variables and clinical variable according to incidence of H. Pylori: In our study we reported that age, site of perforation, size of perforation, duration of perforation, H. Pylori infection, and preoperative shock are the risk factors for the outcome of perforated duodenal ulcer. Mortality and morbidity are increased whenever perforations exceed 24 hours because of peritoneal infection.

Follow up endoscopy: All H. Pylori positive patients after 8 weeks of treatment with anti H. Pylori regimen and PPI were subjected to endoscopy; ulcer recurrence was seen only in one case.

Procedure: we have done simple closure with omental patch in 49 patients. We found $2 \%$ mortality in patients with simple closure with omental patch treatment.

Radiological investigations: Free air was seen under right dome of diaphragm in 49 cases of Du perforation, one case was diagnosed on CT scan.

Site of perforation: Perforation of duodenal ulcer at first part of duodenum situated over anterior wall was commonest (98\%); in one patient site of perforation was second part of duodenum.

Size of perforation: Size of perforation is directly proportional to the complications, bigger the size of perforation higher the incidence of complications.

Totally hospital stay in days: Poor risk patients, stayed for prolonged period in their post operative period because of various complications. The average hospital stay in our study was 7 days for those who underwent simple closure.

Complications of patients studied: among 50 patients studied 10 patients developed complications and remaining 40 patients had smooth recovery. Most common post operative complications were wound infection in about 4 cases. Three had bronchopneumonia, one had renal failure, one patient had burst abdomen, one patient died within 48 hours of post operative period. The patient presented with severe shock and septicemia and dies because of multi organ failure.

CONCLUSION: Duodenal ulcer perforation still remains one of the most common cause of acute abdominal catastrophe, with male preponderance. We conclude that H. Pylori is an important factor in the etiology of duodenal ulcer perforation and accounts for $58 \%$ of cases. In our study we found that duodenal ulcer perforation is a multi factorial disease with alcohol (64\%), smoking (48\%), NSAIDS $(22 \%)$ being common causative factors. The factors significantly related to increased morbidity and mortality are delayed presentation, elderly age group and size of peroration. Omental patch repair either conventional or laparoscopic remains gold standard treatment for perforation. In our study, we determine H. Pylori eradication is effective in short and long term prevention of ulcer recurrence. The ulcer recurrence in our study was only $2 \%$. Hence we conclude that in patients with peptic ulcer disease H. Pylori status should be determined either by endoscopic biopsy or serology and the bacterium should be eradicated in those who are infected, reduces the risk of ulcer recurrence and duodenal perforation.

\section{REFERENCES:}

1. Emergency complications of duodenal ulcer. SCNA 1996

2. Manigots Abdominal Operations 11th edition, Micheal T. Zinner, Stanley W. Ashley 1997.

3. Acute abdomen. Surg Clin N Atm 1997.

4. William Schumer and Sheldono Burman. The perforated viscous diagnosis and treatment in surgical emergency. Surg Clin N Atm 1997. 
5. Naiguiera C, Silva AS, Santos Tn et all. Perforated Peptic ulcer, Main factors of Morbidity and Mortality. World Journal Surgery 2003

6. Bhattacharya Kaushik et al. Peptic ulcer surgery: A historical review. Gastroenterology Today 2002.

7. Hai Ahmad and Srivastava B. Ravindra: Chronic peptic ulcer, stomach and duodenum. ASI Textbook of surgery, 2003; 1 st edition

8. Decker GAG. The stomach, rotation of gut, the duodenum, jejunum. Lee McGregor's Synopsis of Surgical Anatomy, 12 th edition, 1999.

9. Svanes C: Trends in perforated peptic ulcer: Incidence, etiology, treatment and prognosis. World Journal of Surgery 2000.

10. Jarczyls G Katedry et al: Evaluation of early and late results of radical treatment for perforated duodenal ulcer. Pot Juglek, 1996.

\section{AUTHORS:}

1. Sreenidhi G.M.

2. Nandeeshkumar G.N.

\section{PARTICULARS OF CONTRIBUTORS:}

1. Associate Professor, Department of General Surgery, KIMS, Bangalore.

2. Junior Resident, Department of General Surgery, KIMS, Bangalore.

\section{NAME ADDRESS EMAIL ID OF THE} CORRESPONDING AUTHOR:

Dr. Sreenidhi G.M, Associate Professor, KIMS, Bangalore.

Email- dr.nandeeshkumar9@gmail.com

Date of Submission: 13/08/2013.

Date of Peer Review: 14/08/2013.

Date of Acceptance: 16/08/2013.

Date of Publishing: 23/08/2013 